\title{
Glycosphingolipid Functions
}

\section{Clifford A. Lingwood}

In the original version of this article, some of the text labels in Figure 1 were incorrect.

The publisher apologizes for these errors. The correct Figure 1 is reprinted below, and the PDF and HTML versions of the article have been corrected accordingly.

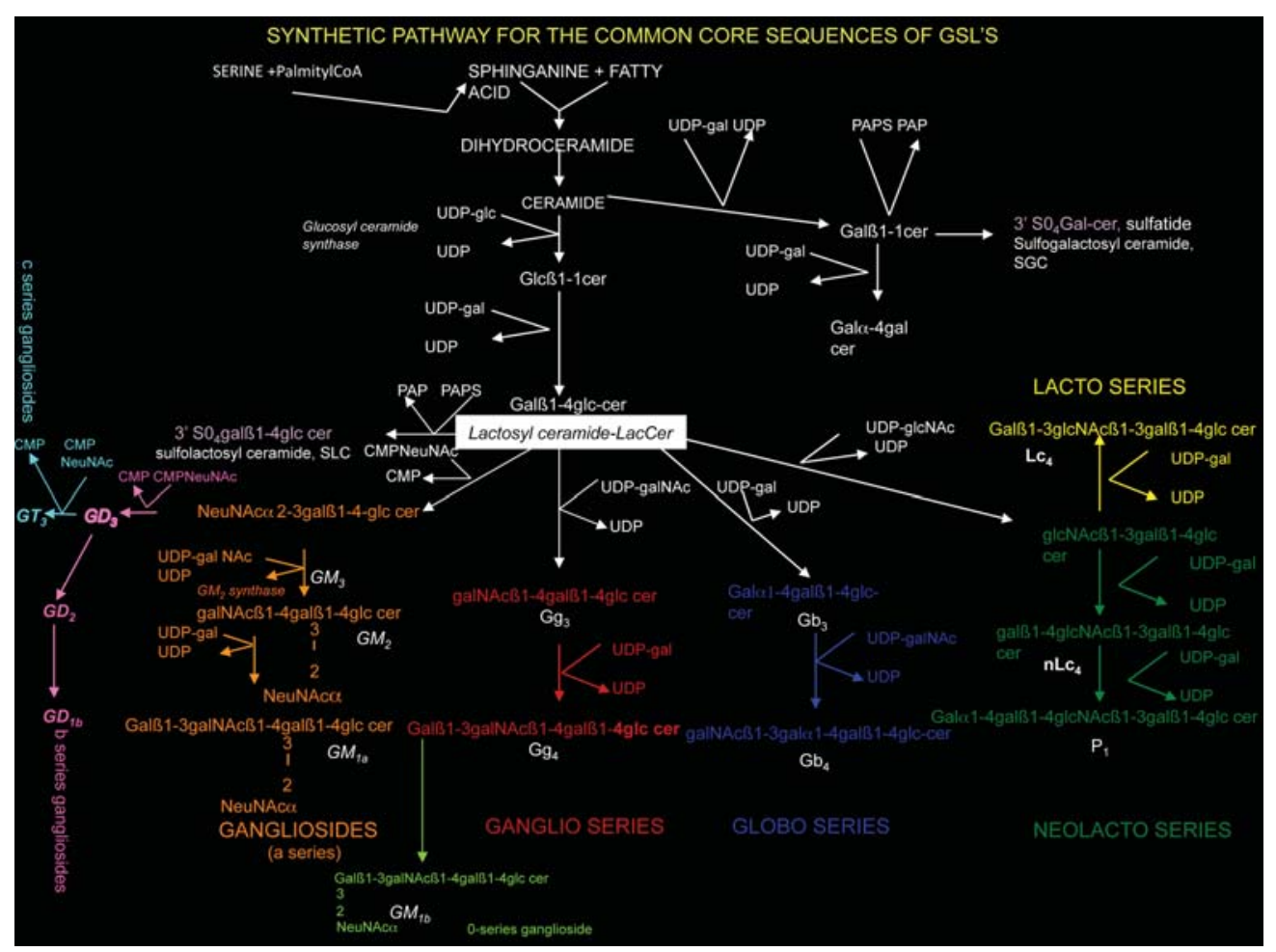

Figure 1. Synthetic pathways for the major GSL species. Glucosyl ceramide is the key precursor for most GSLs and lactosyl ceramide provides the branch point for the different GSL series. 


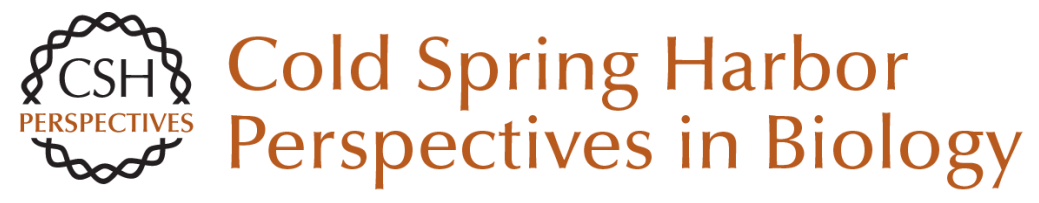

\section{Glycosphingolipid Functions}

Clifford A. Lingwood

Cold Spring Harb Perspect Biol 2011; doi: 10.1101/cshperspect.a011874

Subject Collection The Biology of Lipids

Role of Lipids in Virus Replication Maier Lorizate and Hans-Georg Kräusslich

Model Answers to Lipid Membrane Questions Ole G. Mouritsen

\section{Glycosphingolipid Functions} Clifford A. Lingwood

Regulation of Cholesterol and Fatty Acid Synthesis

Jin Ye and Russell A. DeBose-Boyd

Lipid-Mediated Endocytosis

Helge Ewers and Ari Helenius

Fluorescence Techniques to Study Lipid Dynamics

Erdinc Sezgin and Petra Schwille

Lysosomal Lipid Storage Diseases

Heike Schulze and Konrad Sandhoff

\section{Distribution and Functions of Sterols and}

Sphingolipids

J. Thomas Hannich, Kyohei Umebayashi and Howard Riezman
Membrane Organization and Lipid Rafts Kai Simons and Julio L. Sampaio

Shotgun Lipidomics on High Resolution Mass Spectrometers

Dominik Schwudke, Kai Schuhmann, Ronny Herzog, et al.

Glycosphingolipid Functions Clifford A. Lingwood

Phosphoinositides in Cell Architecture Annette Shewan, Dennis J. Eastburn and Keith Mostov

Synthesis and Biosynthetic Trafficking of Membrane Lipids Tomas Blom, Pentti Somerharju and Elina Ikonen

Lipid Polymorphisms and Membrane Shape Vadim A. Frolov, Anna V. Shnyrova and Joshua Zimmerberg

Specificity of Intramembrane Protein-Lipid Interactions

Francesc-Xabier Contreras, Andreas Max Ernst, Felix Wieland, et al.

Dynamic Transbilayer Lipid Asymmetry Gerrit van Meer

For additional articles in this collection, see http://cshperspectives.cshlp.org/cgi/collection/

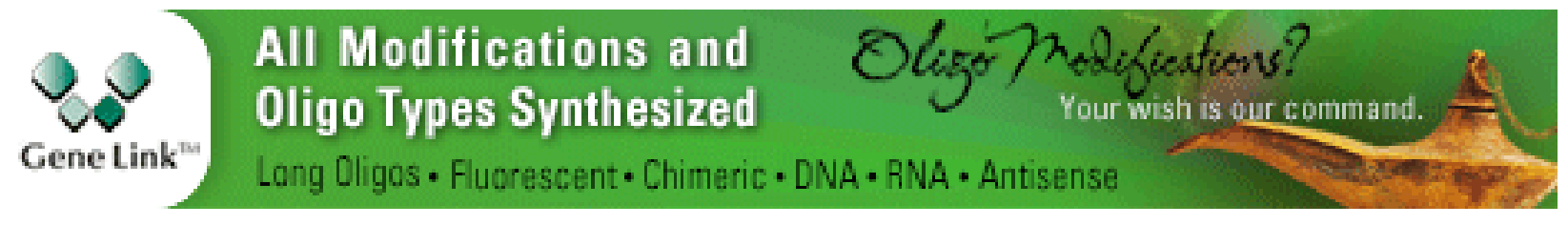

Copyright @ 2011 Cold Spring Harbor Laboratory Press; all rights reserved 